\title{
Nuclear Receptor HNF4 $\alpha$ Binding Sequences are Widespread in Alu Repeats
}

\author{
Eugene Bolotin 1,2,3, Karthikeyani Chellappa', Wendy Hwang-Verslues ${ }^{1,4}$, Jake M Schnabl', Chuhu Yang ${ }^{1,2,5}$ and \\ Frances M Sladek ${ }^{1,2^{*}}$
}

\begin{abstract}
Background: Alu repeats, which account for $\sim 10 \%$ of the human genome, were originally considered to be junk DNA. Recent studies, however, suggest that they may contain transcription factor binding sites and hence possibly play a role in regulating gene expression.

Results: Here, we show that binding sites for a highly conserved member of the nuclear receptor superfamily of ligand-dependent transcription factors, hepatocyte nuclear factor 4alpha (HNF4 $\alpha$, NR2A1), are highly prevalent in Alu repeats. We employ high throughput protein binding microarrays (PBMs) to show that HNF4 $\alpha$ binds $>66$ unique sequences in Alu repeats that are present in $\sim 1.2$ million locations in the human genome. We use chromatin immunoprecipitation (ChIP) to demonstrate that HNF4 $\alpha$ binds Alu elements in the promoters of target genes (ABCC3, APOA4, APOM, ATPIF1, CANX, FEMTIA, GSTM4, IL32, IP6K2, PRLR, PRODH2, SOCS2, TTR) and luciferase assays to show that at least some of those Alu elements can modulate HNF4 $\alpha$-mediated transactivation in vivo (APOM, PRODH2, TTR, APOA4). HNF4 $\alpha$-Alu elements are enriched in promoters of genes involved in RNA processing and a sizeable fraction are in regions of accessible chromatin. Comparative genomics analysis suggests that there may have been a gain in HNF4 $\alpha$ binding sites in Alu elements during evolution and that non Alu repeats, such as Tiggers, also contain HNF4 $\alpha$ sites.
\end{abstract}

Conclusions: Our findings suggest that $\mathrm{HNF} 4 \alpha$, in addition to regulating gene expression via high affinity binding sites, may also modulate transcription via low affinity sites in Alu repeats.

\section{Background}

As much as $50 \%$ of the $\sim 3$ billion base pairs in the human genome may be derived from repetitive DNA sequence [1]. While repetitive DNA is often referred to as "junk" DNA, even when that term was originally coined it was hypothesized that junk DNA may play an active role in genome function [2]. The notion that repetitive DNA may play a regulatory role and be involved in the evolution of gene regulation was also postulated early on, although it was not until recently that there was evidence to support those ideas [3-5].

A major category of repetitive DNA is short interspersed nuclear elements (SINEs), which are believed to have originated from the 7SL RNA gene that is part of the ribosome complex [6]. In the human genome, the

\footnotetext{
* Correspondence: frances.sladek@ucr.edu

'Department of Cell Biology and Neuroscience, University of California, Riverside, Riverside, CA, 92521, USA Full list of author information is available at the end of the article
}

largest class of SINEs are Alu repeats, which at $\sim 1.2$ million copies account for $\sim 10 \%$ of the human genome [1]. Alu elements were first characterized as $\sim 300$ nucleotide repetitive sequences that contain an AluI restriction site (5'-AGCT-3') from the bacterium Arthrobacter luteus $[7,8]$. Alu elements, which are still mobile in the human genome by virtue of the action of a LINE1 reverse transcriptase [9], are a relatively recent occurrence evolutionarily. They are found exclusively in primates, including humans, and hence are postulated to have entered the mammalian genome $\sim 60-65$ million years ago [10].

Alu elements have been implicated in several human diseases including leukemia, hemophilia and breast cancer, suggesting that their impact on human health may be significant [11]. There are several well characterized examples of Alu insertions affecting splicing patterns and hence protein function [12]. A variety of transcription factor (TF) binding sites (TFBSs) have also been
C Biomed Central 
characterized in Alu elements, including sites for YY1 [13], Sp1 [14], tumor suppressor p53 [15], homeodomain and TATA binding proteins [16]. Nuclear receptors (NR), which belong to a superfamily of liganddependent TFs, have also been found to have binding sites in Alu elements: retinoid acid receptor (RAR, NR1B) [17], estrogen receptor (ER, NR3A) [18,19], progesterone receptor (PR, NR3C3) [20] and vitamin D receptor (VDR, NR1I1) [21]. Alu insertions have also been shown to alter the expression of at least six human genes: CD8a (CD8A), keratin 18 (KRT18), parathyroid hormone $(P T H)$, Wilm's tumor 1 (WT1), receptor for Fc fragment of IgE, high affinity I, gamma polypeptide (FCER1G) and breast cancer 1, early onset (BRCA1) [22]. Therefore, Alu sequences may regulate the level of transcripts and hence proteins in the cell, as well as the function of those proteins.

Hepatocyte nuclear factor 4 alpha, (HNF4 $\alpha$, NR2A1) is a member of the NR superfamily that is highly expressed in the liver, as well as the kidney, intestine (large and small), pancreas and stomach [23]. HNF4 $\alpha$ is best known for its role in the adult liver and pancreas, as well as in early development [24,25]; it also has an emerging role in the gut [26-28]. The HNF4A gene is mutated in an inherited form of type 2 diabetes, maturity onset diabetes of the young 1 (MODY1) [29], and was recently identified as a susceptibility locus in inflammatory bowel disease (IBD) [30]. Mutations in HNF4 $\alpha$ binding sites have also been directly linked to human diseases, including hemophilia and MODY3 $[31,32]$. Many NRs are common drug targets [33]; the recent identification of the endogenous ligand of HNF4 $\alpha$ that binds in a reversible fashion also makes HNF4 $\alpha$ a potential drug target $[34,35]$.

In addition to its medical relevance, $\mathrm{HNF} 4 \alpha$ also appears to play a unique role in the evolution of NRs. It is highly conserved across species, with $100 \%$ amino acid conservation in the DNA binding domain of all mammalian HNF4 $\alpha$. While HNF $4 \alpha$ is most similar to the retinoid $\times$ receptor alpha $(\mathrm{RXR} \alpha, \mathrm{NR} 2 \mathrm{~B} 1)$, unlike many other NRs, it does not heterodimerize with RXR. Rather, it binds DNA in the form of direct repeats separated by one nucleotide (DR1, AGGTCAxAGGTCA) exclusively as a homodimer [36]. HNF4 $\alpha$ has been found in every animal organism examined thus far, including sponge and coral [37], and has been postulated to be the ancestor of the entire NR family [38].

Many hundreds of HNF4 $\alpha$ target genes have been identified by both classical promoter analysis as well as more modern genome-wide studies [32,39-41]. During one such genomic study, we observed a very uneven frequency profile of individual HNF4 $\alpha$ binding sequences [42]. Specifically, we noted that a certain DNA sequence designated H4.141 (5'-AGGCTGaAGTGCA-3') was >
100 -fold overrepresented compared to other HNF4 $\alpha$ binding sites in the human, but not the mouse, genome (see additional file 1: Figure S1). In the current study, we investigate the notion that these and other HNF4 $\alpha$ binding sequences are in Alu repeats. We use the powerful high throughput technology of protein binding micorarrays (PBMs) to show that HNF4 $\alpha$ does indeed bind numerous sequences in Alu repeats in vitro. We perform ChIP and luciferase assays to show that HNF4 $\alpha$ binds at least some Alu sequences in vivo and that those binding events are associated with transcriptional activation. Finally, we investigate accessibility of these sites by correlation with DNase hypsersensitivity data and evolutionary conservation by comparative genomic analysis.

\section{Results \\ HNF $4 \alpha$ binds Alu repeats in vitro}

Since genome-wide location analysis (i.e., ChIP-chip/seq) often filters out or cannot distinguish the exact location of TF binding events in highly repetitive DNA, we took a combined in vitro/in silico approach to determine whether HNF4 $\alpha$ binds Alu elements. We generated a custom protein binding microarray (PBM3) that contained 200 unique Alu-associated sequences (Figure 1). Since RAR was previously shown to bind DR2-like sequences (AGGTCAxxAGGTCA) in Alu repeats [17] and since we have previously shown that $\mathrm{HNF} 4 \alpha$, while preferring DR1s, can also bind DR2s [43], we also put on the PBM 1470 permutations of DR1 and DR2 sequences as well as $\sim 150$ random controls and $\sim 2000$ additional sequences in the human genome predicted by a support vector machine (SVM) algorithm to bind HNF4 $\alpha$ [42]. Each sequence was replicated four times for a total of more than 15,000 spots of DNA.

We found that human HNF $4 \alpha 2$ bound 66 out of 200 Alu-derived 13-mers in a significant fashion (> 2 SD better than random controls, $\mathrm{p}$-value $<0.045$ for the lowest binder) (Figure 2A). It also bound 994 out of 3796 non Alu-derived sequences, although eight of those sequences were subsequently found also to be associated with Alu repeats at a frequency of $>90 \%$. An exact match search of the entire human genome (hg18) with the 1060 sequences that bound HNF4 $\alpha$ in the PBM $(66+994)$ showed that there are a total of $1,320,513$ occurrences of those HNF4 $\alpha$ binding sites in the genome and that the vast majority $(94.9 \%$, $1,252,918)$ are in repetitive elements, of which most $(95.7 \%, 1,198,534)$ are in Alu repeats (Figure 2A). This number is much greater than that previously found for RAR binding sites in Alu elements but that is most likely due to the fact that strict DR1 and DR2 consensus sequences were used for the genomic search [17]. 


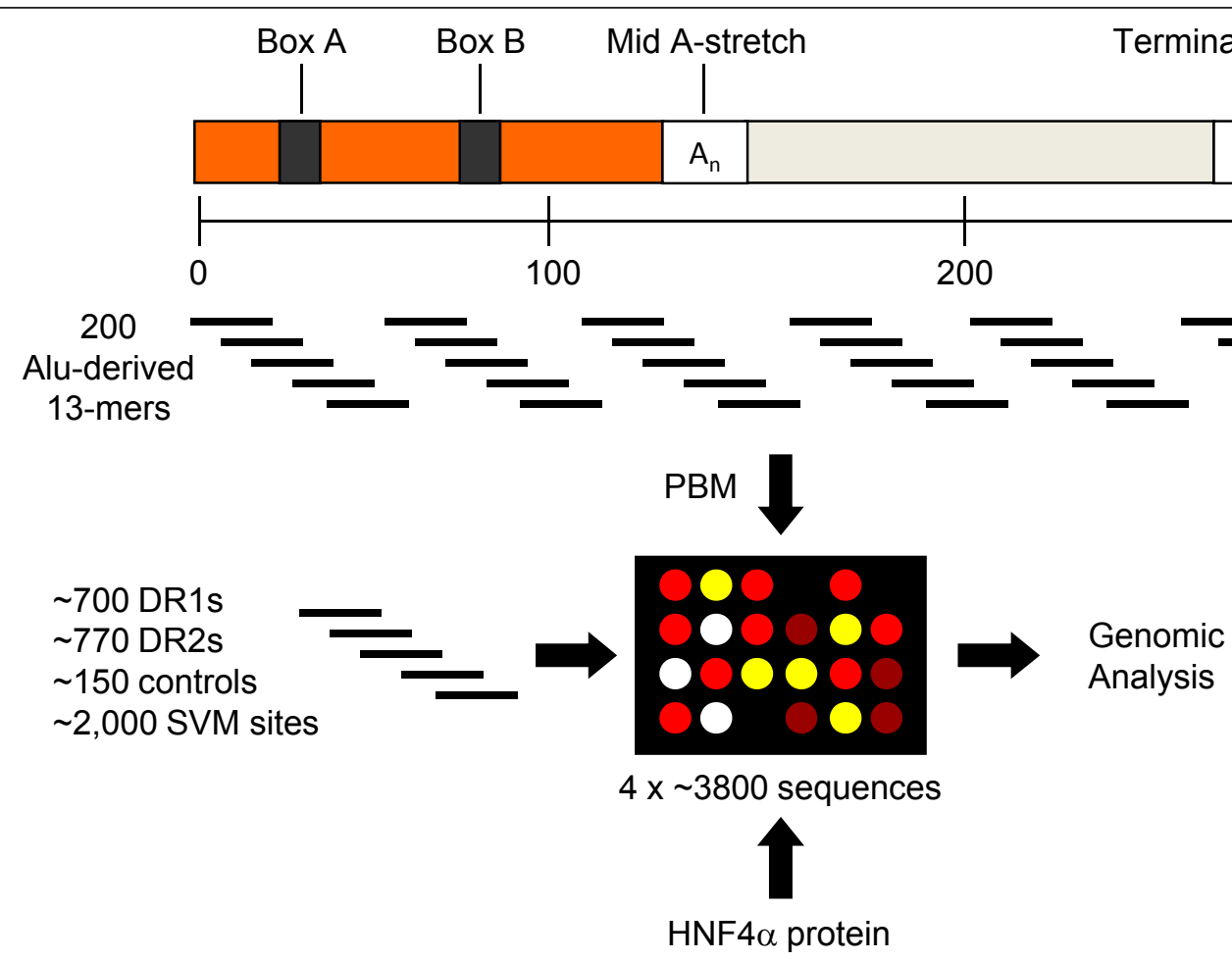

Figure 1 Schematic diagram of the protein binding microarray (PBM) designed to test the ability of HNF4 $\alpha$ to bind Alu-derived DNA sequences. Top, schematic structure of a generic Alu element ( 300 nt long) comprised of two related, but non identical monomers, the right and left arms (adapted from [75]). Box A and B are RNA Pol III internal promoters. Relative positions of the 200 Alu-derived 13-mers incorporated into PBM3 are also shown. Bottom, remaining DNA probes on PBM3 and workflow.

The position weight matrices (PWM) of the DR1- and DR2-derived sequences bound by HNF4 $\alpha$ were essentially identical and suggested that for HNF4 $\alpha$ the core of CAAAG is more relevant than the AGGTCA half sites (Figure 2B). Interestingly, the PWM of the Aluderived 13 -mers bound by HNF $4 \alpha$ did not contain a prominent CAAAG core but did contain an identifiable AGGTCA half site on the right hand side; the left hand portion was primarily C-rich. Overall, the Alu-derived PWM strongly resembled the non canonical HNF $4 \alpha$ PWM we identified in our previous PBM study [42], although the association of the non canonical motif with Alu elements was not investigated. A partial list of DNA sequences significantly bound by HNF4 $\alpha$ in the PBM and their estimated frequencies in Alu repeats and the human genome (hg18) is given in Table 1 (see additional file 2: Table S1 for the complete list of HNF4 $\alpha$ bound motifs associated with Alu repeats).

\section{HNF4 $\alpha$ binds Alu repeats in the promoter region of target genes in vivo}

To investigate HNF4 $\alpha$ binding to Alu repeats in the promoters of HNF4 $\alpha$ target genes in vivo, we performed a ChIP assay for HNF4 $\alpha$ in human hepatocellular carcinoma HepG2 cells that express HNF4 $\alpha$ and many of its target genes. Several criteria were used for selecting potential Alu sequences for ChIP analysis. First, the Alu element had to contain a probable HNF4 $\alpha$ binding site based on the PBM results. Second, the gene containing the Alu element had to be down regulated $>1$.4-fold by HNF4 $\alpha$ RNAi in HepG2 cells as determined by expression profiling [42]. Third, the Alu repeat had to be within $-5 \mathrm{~kb}$ to $+1 \mathrm{~kb}$ of the transcription start site (TSS) of the gene. Fourth, the Alu element had to be amenable to primer design and PCR amplification, non trivial criteria due to the repetitive nature of the sequences. Overall, 47 sets of primers for 35 genes were designed, of which 15 sets gave a specific signal from the input control, indicating appropriate amplification of the Alu sequence. Finally, of those 15 primer sets, 13 genes yielded a significant signal in the HNF4 $\alpha$ ChIP assay compared to the corresponding negative control IgG (Figure 3). These results indicate that HNF4 $\alpha$ binds the Alu elements in the promoter regions of these target genes in vivo.

\section{HNF $4 \alpha$ activates transcription from Alu elements}

In order to determine whether the binding of HNF4 $\alpha$ to the Alu elements observed in vivo could drive transcription, we subcloned into a luciferase reporter construct 


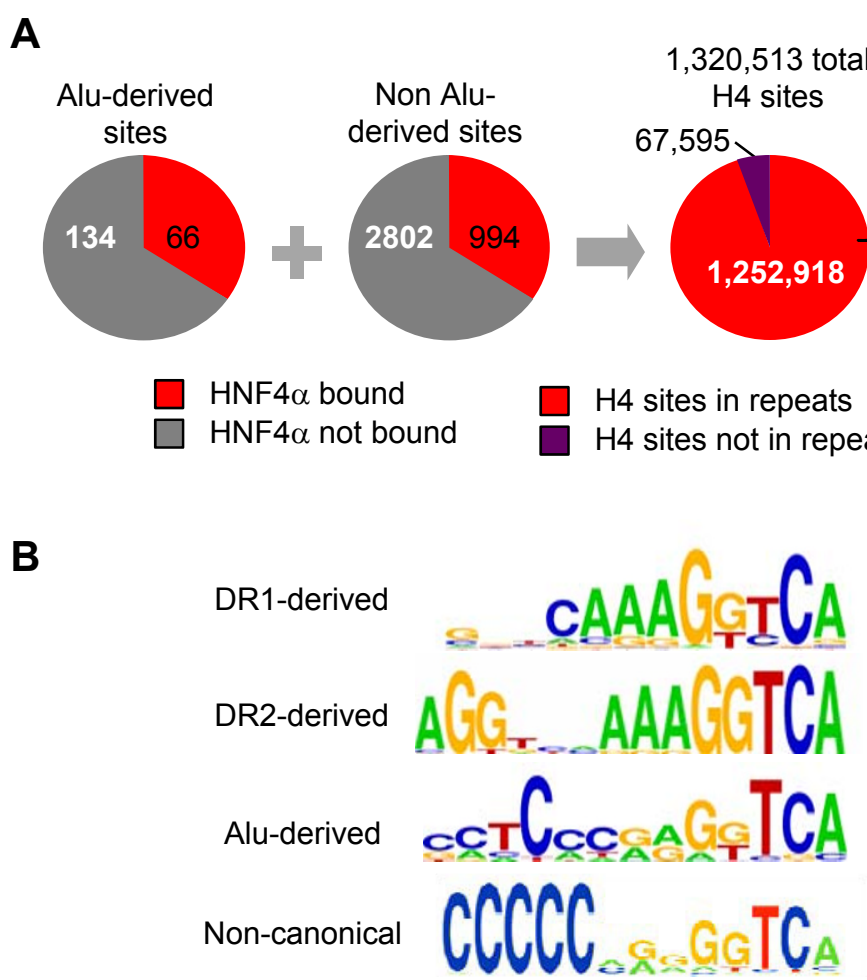

Figure 2 The vast majority of HNF4 $\alpha$ binding sites in the human genome are found in Alu repeats. A. Numerical results from PBM3 described in Fig. 1 and in the text. B. Position weight matrices (PWMs) generated with Weblogo [76] of sequences bound by human HNF4 2 in the PBM, categorized by the type of sequence. The DR1-derived PWM was from 994 sequences bound by HNF4 $\alpha 2$, the DR2-derived PWM from 50 sequences and the Alu-derived sequences from 66 sequences. The non canonical PWM is from Bolotin et al. [42].

with a minimal core promoter the PCR fragments containing the Alu element with the HNF4 $\alpha$ binding site (HNF4 $\alpha$-Alu element). Three of the genes ChIP'd by HNF4 $\alpha$ in HepG2 cells were analyzed - APOM, TTR and PRODH2. Transient transfection into an HNF4 $\alpha$ responsive cell line (HEK 293T) showed that HNF4 $\alpha 2$ significantly transactivates the luciferase constructs in a dose-dependent manner (Figure 4A). While the fold induction was not large (1.5 to 2.7 -fold), it was comparable to two reporter constructs containing a single classical HNF $4 \alpha$ response element (2.0- and 4.8-fold) (Figure 4B). To determine whether an HNF4 $\alpha$-Alu element could contribute to transcription of a native promoter, we analyzed the $A P O A 4$ promoter construct that contained both an HNF4 $\alpha$-Alu element as well as a classical HNF4 $\alpha$ response element. The wildtype (WT) promoter was transactivated well by HNF4 $\alpha$ (4.9-fold) and mutations in the HNF4 $\alpha$ binding site in either the Alu element or the classical response element reduced the transactivation (to 3.4- and 3.2-fold, respectively) (Figure $4 \mathrm{C})$. While the effect of the mutation in the HNF4 $\alpha$-Alu site was not large, it was statistically signficant $(\mathrm{p}<$ 0.001 ) and comparable to the mutation in the classical site. Taken together, these results indicate not only that
HNF4 $\alpha$ binds Alu elements in the promoters of HNF4 $\alpha$ target genes in vivo, but also that this binding can contribute to the overall transcriptional activity of the gene.

\section{Frequency of HNF4 $\alpha$ sites in Alu and non Alu repeats}

In order to determine the prevalence of HNF4 $\alpha$ binding sites in Alu elements, a search of all the Alu repeats in the human genome (hg18) was performed with the 1060 $(66+994)$ sequences bound by HNF4 $\alpha$ in PBM3; the vast majority of hits were obtained with the $66+8$ Alu-derived sequences. Approximately $\sim 750,000$ out of $\sim 1,175,000$ Alu repeats in Repeat Masker ( 64\%) were found to contain at least one DNA sequence to which HNF4 $\alpha$ bound in PBM3; there was also a substantial number of Alu repeats $(\sim 338,000, \sim 45 \%)$ that contained more than one HNF4 $\alpha$ binding site (Table 2). All told there were nearly $\sim 1.2$ million HNF $4 \alpha$ binding sites in Alu repeats in the human genome.

Different families of Alu repeats were found to have different frequencies of HNF4 $\alpha$ sites (Table 3) and within a given Alu family there was a range of frequencies (Table 4). There was also a rough negative correlation between the percentage of Alu elements within a given family that contained an HNF4 $\alpha$ binding site and 
Table 1 Frequency of Alu-derived sequences bound by $H N F 4 \alpha$ in Alu repeats and the human genome.

\begin{tabular}{|c|c|c|c|c|}
\hline Sequence & PBM score & \# in Alus & \# in hg18 & $\%$ \\
\hline TGACCTCGTGATC & 0.62 & 101229 & 101259 & 99.97 \\
\hline TGAACCCGGGAGG & 0.76 & 122111 & 122158 & 99.96 \\
\hline TGAACCTGGGAGG & 0.73 & 126196 & 126368 & 99.86 \\
\hline TGACCTCATGATC & 0.68 & 41447 & 41545 & 99.76 \\
\hline TGAACCCGGGAGA & 0.61 & 5700 & 5716 & 99.72 \\
\hline TGGGGTTTCACCG & 0.70 & 13385 & 13428 & 99.68 \\
\hline TGAACCCGGAAGG & 0.69 & 4520 & 4535 & 99.67 \\
\hline TGACCTTGTGATC & 0.64 & 40637 & 40786 & 99.63 \\
\hline TGAACTCGGGAGG & 0.82 & 6783 & 6810 & 99.60 \\
\hline GCACTTTGGGAGG & 0.84 & 469851 & 471728 & 99.60 \\
\hline TGAATCCGGGAGG & 0.72 & 5765 & 5789 & 99.59 \\
\hline ACACTITGGGAGG & 0.69 & 38828 & 38993 & 99.58 \\
\hline GCACTTCGGGAGG & 0.87 & 8683 & 8721 & 99.56 \\
\hline TGACCTCGCGATC & 0.77 & 775 & 779 & 99.49 \\
\hline TGAACCCGAGAGG & 0.62 & 4133 & 4156 & 99.45 \\
\hline GTACTITGGGAGG & 0.63 & 15294 & 15386 & 99.40 \\
\hline TGAACCCGGGGGG & 9.02 & 1319 & 1328 & 99.32 \\
\hline TGACCTTGCGATC & 0.73 & 411 & 414 & 99.28 \\
\hline TGACCTCGTGATT & 0.63 & 2863 & 2888 & 99.13 \\
\hline GCACTCTGGGAGG & 0.74 & 13202 & 13342 & 98.95 \\
\hline TGAGCCCGGGAGG & 0.71 & 5450 & 5517 & 98.79 \\
\hline TGAGCCTGGGAGG & 0.69 & 19616 & 19895 & 98.60 \\
\hline TGACCTCGTGACC & 0.67 & 1070 & 1088 & 98.35 \\
\hline TGACCTCGTGACC & 0.68 & 1070 & 1088 & 98.35 \\
\hline TGAACGCGGGAGG & 0.72 & 642 & 653 & 98.32 \\
\hline TGACCTCAAATGA & 0.63 & 8625 & 8779 & 98.25 \\
\hline
\end{tabular}

PBM score is the average relative intensity of quadruplicate spots across four arrays. Score $>.612$ indicates significant binding.

the age of the family. The newest Alu family, AluY ( $\sim 25$ Mya), had the greatest percentage of HNF4 $\alpha$ sites ( 91\%); the second newest family, AluS ( 30-55 Mya), had the next highest percentage $(\sim 75 \%)$ and the oldest family, Alu J ( 55-65 Mya), had the lowest percentage ( 33\%) (Table 3) [9]. This correlation held for the precursors to the Alu family as well. FAM (free Alu-like monomer) sequences are Alu precursors that gave rise to FRAM (free right Alu monomer) and FLAM (free left Alu monomer) sequences that eventually joined to create the modern dimeric Alu element [44]. The frequency of the HNF $4 \alpha$ binding sites in FAM $(0.34 \%)$, FRAM $(11.84 \%)$ and FLAM_C $(233.77 \%)$ suggests that the HNF4 $\alpha$ sites may have first appeared in Alu-like sequences in the FLAM family. Interestingly, not only does AluJ have a similar frequency of HNF4 $\alpha$ sites as FLAM_C, but the HNF4 $\alpha$ sites in AluJ are almost exclusively in the left arm at position 31 (Figure 5). In contrast, the newer AluS family has significant secondary sites at positions 62 and 200 while the newest Alu family, AluY, has essentially the same number of HNF4 $\alpha$ sites at position 62 as at position 31, although the number of sites at position 200 has remained relatively low. All told, these results suggest that there has been a gain of HNF $4 \alpha$ binding sites in Alu elements during the course of evolution. (See see additional file 2: Table S3 for a complete list of Alu repeats with HNF4 $\alpha$ binding sites and their frequency in the human genome.)

The human genome search also revealed $\sim 54,000$ occurrences of HNF4 $\alpha$ sites in non Alu repeats (Figure 2A). The non Alu repeat families were numerically dominated by repeats referred to as mammalian interspersed repeats (MIRs), LINE2 elements (L2) and Tigger (Table 5). However, while only $\sim 1 \%$ of the MIRs and L2s possess an HNF4 $\alpha$ binding site, more than $\sim 20 \%$ of Tiggers do. In addition, more than $50 \%$ of the SVA family of retrotransposons contain at least one HNF $4 \alpha$ site, although this is not surprising since these elements contain a portion of an Alu element (see additional file 2: Table S4 for a complete list of frequencies of HNF4 $\alpha$ binding sites in non Alu repeats).

\section{Frequency of HNF4 $\alpha$-Alu elements in promoters and DNase hypersensitive sites}

Others have shown that the region 5000 bp upstream from the TSS $(+1)$ contains on average 3.63 Alu elements [45]. We analyzed the same promoter region and found that every human gene has on average 2.91 HNF4 $\alpha$-Alu elements, consistent with the overall high proportion of Alu elements with an HNF4 $\alpha$ site (Tables 3 and 4). To determine which Alu elements may be accessible, and hence potentially play a role in transcription regulation, we determined the number of HNF4 $\alpha$ Alu elements that reside within DNase hypersensitive regions using datasets from the ENCODE project $[46,47]$. Genome-wide 46,129 HNF4 $\alpha$-Alu elements ( $6.2 \%$ of all HNF4 $\alpha$-Alu's) are within DNase hypersensitive regions across mutliple cell lines, with 5458 genes containing one or more HNF4 $\alpha$-Alu/DNase sites in their $5 \mathrm{~kb}$ promoter region. 7000 HNF4 $\alpha$-Alu elements are in DNase hypersensitive regions in HepG2 cells alone (6212 from Rep Track 1 and 8127 from Rep Track 2). While these findings may be an underestimate due to the difficulty of sequencing through repetitive elements, they nonetheless indicate that while the majority of the $\sim 750,000$ HNF4 $\alpha$-Alu elements may not be accessible in most cell types, a sizeable portion of HNF4 $\alpha$-Alu elements are in regions of open chromatin and hence may be transcriptionally active.

\section{Age of Alu repeats in HNF4 $\alpha$ target genes}

In order to estimate the age of the various HNF4 $\alpha$-Alu elements, we determined the presence of the Alu elements bound by HNF4 $\alpha$ in the HepG2 ChIP assay in four sequenced primate genomes - marmoset, rhesus, 


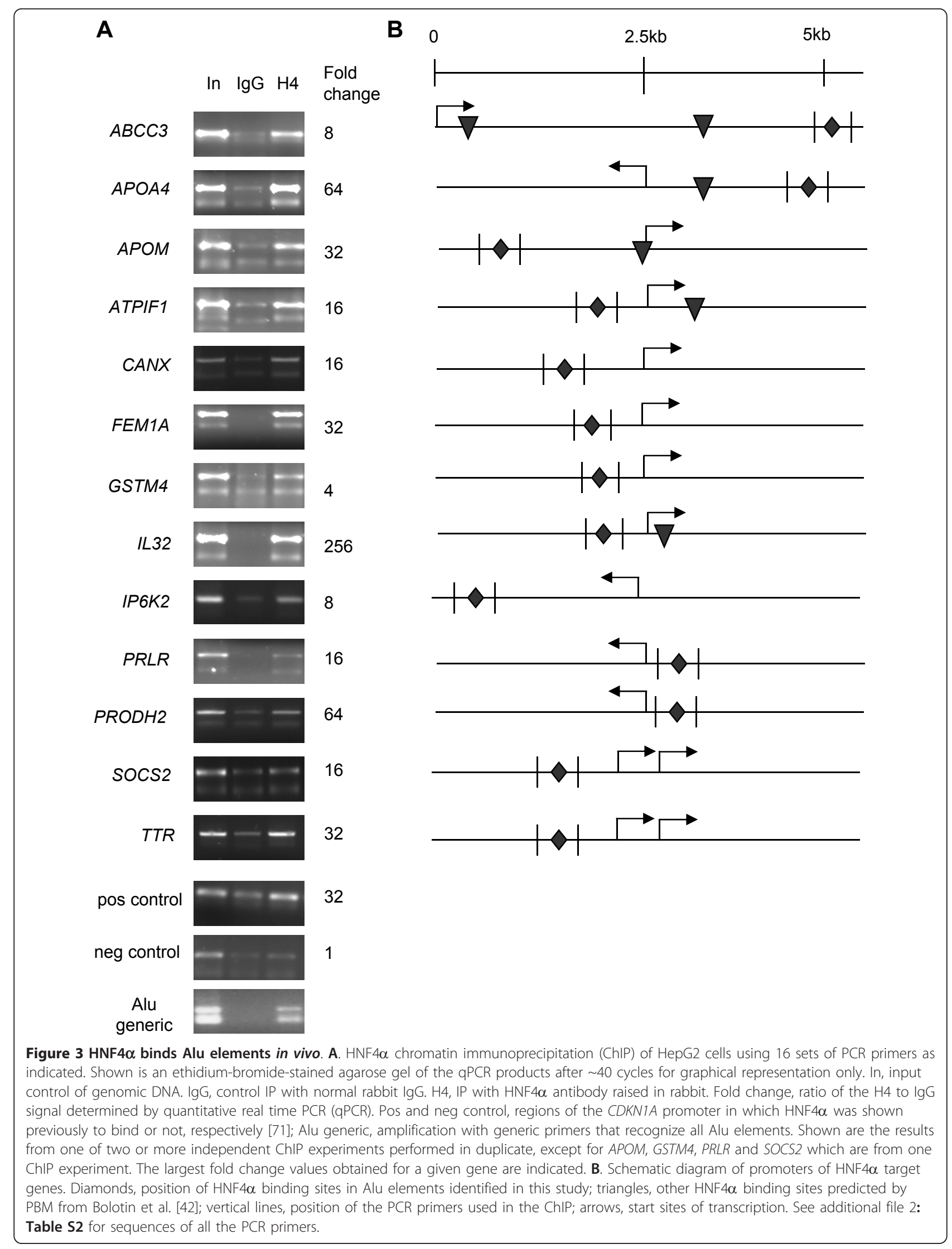




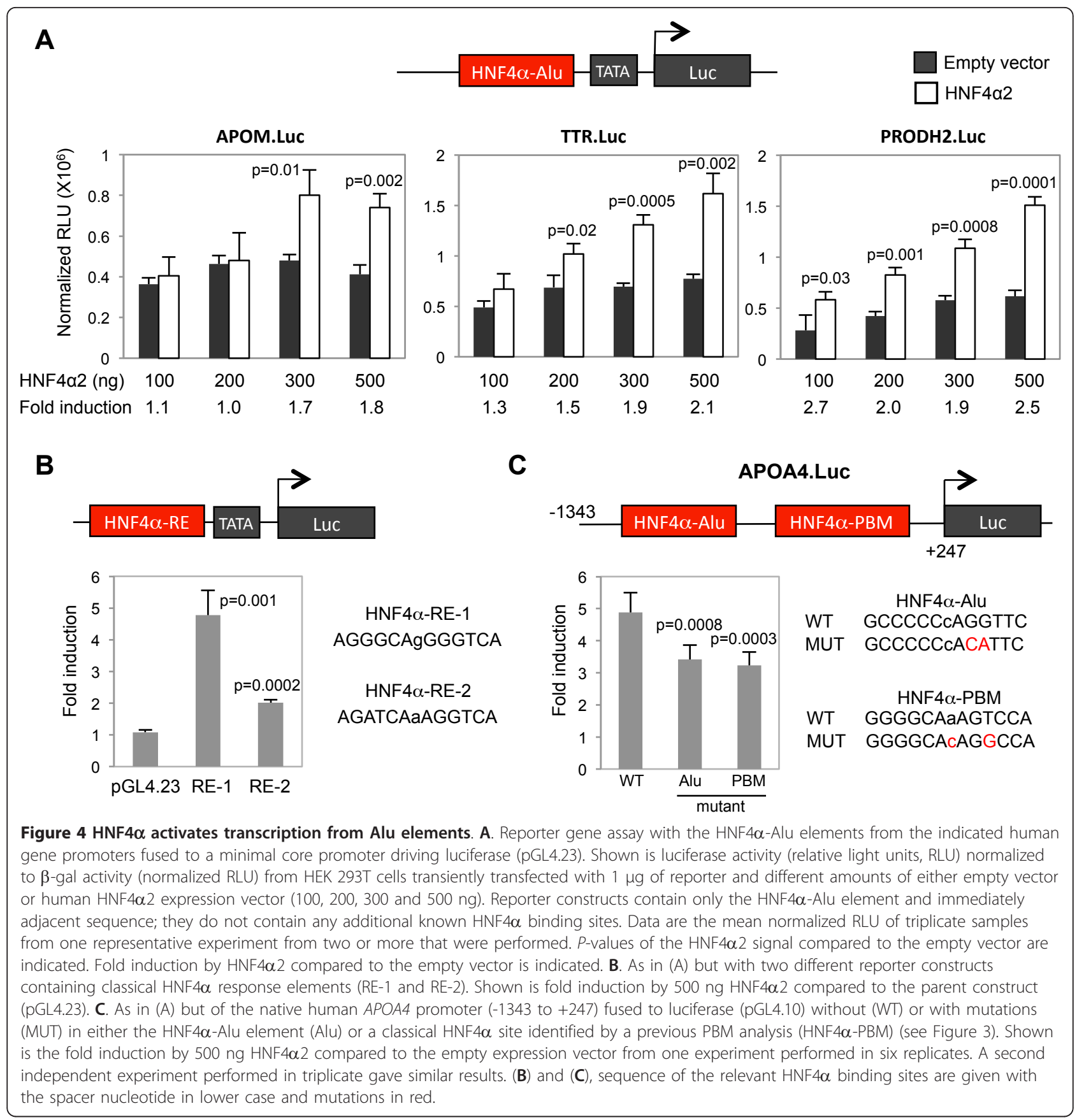

Table 2 Number of Alu repeats with HNF4 $\alpha$ binding sites in the human genome (hg 18).

\begin{tabular}{ccc}
\hline \# of H4 sites in Alu & \# of Alus & Total \# of H4 sites \\
\hline 1 & 409,466 & 409,466 \\
2 & 234,592 & 469,184 \\
3 & 94,548 & 283,644 \\
4 & 8762 & 35,048 \\
5 & 232 & 1160 \\
6 & 4 & 24 \\
8 & 1 & 8 \\
Total & 747,605 & $1,198,534$
\end{tabular}

Table 3 Alu families in human genome (hg18) with HNF4 $\alpha$ binding sites.

\begin{tabular}{cccr}
\hline Alu & \# with H4 & \# in hg18 & \% \\
\hline AluY & 128,437 & 140,510 & 91.41 \\
AluS & 507,971 & 675,017 & 75.25 \\
AluJ & 102,628 & 307,445 & 33.38 \\
FRAM & 1005 & 8490 & 11.84 \\
FLAM_C & 7509 & 22,235 & 33.77 \\
FLAM_A & 39 & 16,050 & 0.24 \\
FAM & 16 & 4771 & 0.34 \\
\hline
\end{tabular}


Table 4 Alu subfamilies in human genome (hg18) with HNF4 $\alpha$ binding sites.

\begin{tabular}{cccr}
\hline Alu & \# with H4 & \# in hg18 & \% \\
\hline AluYa5 & 3776 & 3851 & 98.05 \\
AluYf5 & 173 & 178 & 97.19 \\
AluY & 112,814 & 118,382 & 95.30 \\
AluYk4 & 1720 & 1831 & 93.94 \\
AluSg & 37,876 & 40,751 & 92.94 \\
AluYb9 & 296 & 323 & 91.64 \\
AluYb8 & 2526 & 2811 & 89.86 \\
AluSc & 30,426 & 33,886 & 89.79 \\
AluSg7 & 7268 & 8207 & 88.56 \\
AluSc8 & 19,011 & 21,491 & 88.46 \\
AluSg4 & 6493 & 7347 & 88.38 \\
AluYc3 & 492 & 566 & 86.93 \\
AluSc5 & 5709 & 6766 & 84.38 \\
AluYf4 & 1128 & 1353 & 83.37 \\
AluSx3 & 23,542 & 28,952 & 81.31 \\
AluSp & 39,357 & 49,055 & 80.23 \\
AluSx4 & 4499 & 5658 & 79.52 \\
AluSq4 & 1086 & 1393 & 77.96 \\
AluSq2 & 41,871 & 54,418 & 76.94 \\
AluSq & 16,472 & 21,472 & 76.71 \\
AluYd8 & 167 & 221 & 75.57 \\
\hline
\end{tabular}

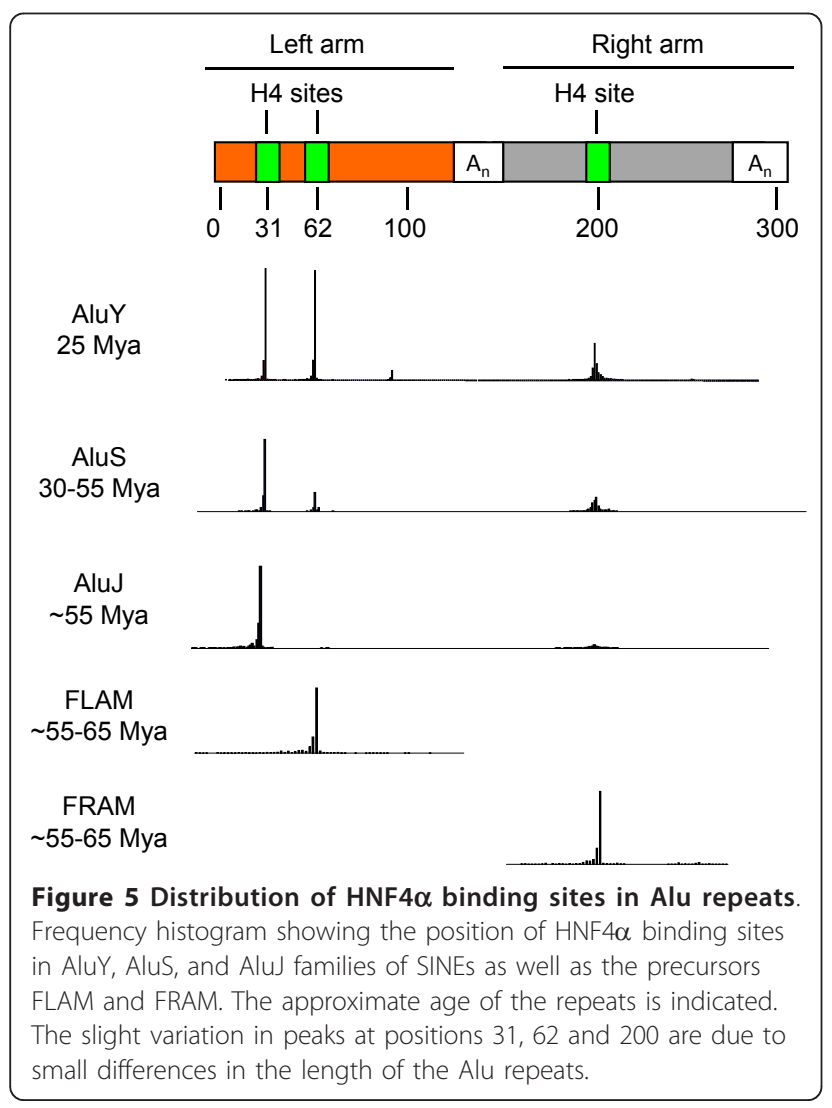

orangutan and chimpanzee. The first mammalian primate originated $\sim 60$ million years ago (Mya). The marmoset monkey branched off from the human lineage $\sim 35$ Mya, the rhesus monkey 25 Mya, the orangutan $\sim 8$ Mya and the chimpanzee $\sim 5.5$ Mya [48]. The results show that all of the HNF4 $\alpha$-Alu elements examined are older than humans (Figure 6), which is not surprising since only $~ 5,000$ or $0.5 \%$ of Alus are human-specific [9]. Five of the ChIP'd HNF4 $\alpha$-Alu elements (in $A B C C 3$, ATPIF1, PRLR, TTR, SOD2) were common among all the primate genomes, and thus fairly ancient (> 35 million years old). An additional two elements (in APOA4 and SOCS2) also appear to be about 35 million years old but may have been lost after chimps diverged from the primate lineage. In contrast, five of the HNF4 $\alpha$-Alu elements (in CANX, FEM1A, GSTM4, IP6K2, PRODH2) appear to be somewhat newer ( 25 million years old) due to their presence in all primates except marmoset. The two most recent elements ( $\sim 8$ million years old) appear to be in the IL32 and APOM genes since they are found only in orangutan, chimp and human. The AluSq2 element in the IL32 gene, however, could be older due to the fact that an entire region of the chromosome, including the IL32 gene, is missing in rhesus (Figure 7A). In the APOM gene, our ChIP results could not distinguish whether the HNF4 $\alpha$ site is in AluJr or AluSg7; it is also curious that the AluSg7 element is only partially missing in both rhesus and marmoset (Figure $7 \mathrm{~B})$. The AluSp element in the PRODH2 promoter, in contrast, appears to have entered the primate lineage after the divergence of the marmoset ( 35 Mya) but before the divergence of the rhesus monkey (25 Mya), consistent with the reported age of the AluS subfamily (30-55 Mya) (Figure 7C). Assuming that the absence of the HNF4 $\alpha$-Alu elements are not due simply to errors in genome assembly and/or misclassification of Alu elements, these results suggest that HNF4 $\alpha$-Alu elements could play a role in differential regulation of these genes in different primate species.

\section{Discussion}

The functional relevance of repetitive DNA such as Alu repeats in the human genome has been debated ever since they were first discovered several decades ago. In this study, we show that the nuclear receptor HNF4 $\alpha$ binds Alu-derived 13-mers in vitro as well as Alu elements in the promoters of HNF4 $\alpha$ target genes in vivo. We show that HNF4 $\alpha$ sites in Alu elements can drive gene expression in luciferase assays and that HNF $4 \alpha$ binding sites are found in $\sim 64 \%$ of all known Alu repeats in the genome $(\sim 1.2$ million HNF4 $\alpha$ sites in $\sim 750,000$ Alu elements). Additionally, we found that while HNF4 $\alpha$ sites are predominantly found in Alu repeats, they are also found in other repeats such as 
Table 5 Non Alu repeat families in human genome (hg18) with HNF4 $\alpha$ binding sites.

\begin{tabular}{|c|c|c|c|c|c|c|c|}
\hline \multicolumn{4}{|c|}{ Sorted by number of HNF $4 \alpha$ sites } & \multicolumn{4}{|c|}{ Sorted by prevalence of HNF4 $\alpha$ sites } \\
\hline Transposon & \# with H4 & \# in hg18 & $\%$ & Transposon & \# with H4 & \# in hg18 & $\%$ \\
\hline MIRb & 2333 & 223,605 & 1.04 & SVA_C & 215 & 281 & 76.51 \\
\hline L2a & 2256 & 169,417 & 1.33 & SVA_B & 341 & 465 & 73.33 \\
\hline MIR & 1586 & 173,924 & 0.91 & SVA_D & 932 & 1370 & 68.03 \\
\hline $\mathrm{L} 2 \mathrm{C}$ & 1455 & 139,570 & 1.04 & SVA_A & 132 & 259 & 50.97 \\
\hline Tigger2a & 1186 & 3,316 & 35.77 & $(C C G G A) n$ & 1 & 2 & 50.00 \\
\hline L2b & 1050 & 96,999 & 1.08 & HSATI & 19 & 42 & 45.24 \\
\hline FRAM & 1005 & 8,490 & 11.84 & LTR22A & 80 & 187 & 42.78 \\
\hline SVA_D & 932 & 1,370 & 68.03 & Tigger2a & 1186 & 3316 & 35.77 \\
\hline L2 & 898 & 56,019 & 1.60 & HERV-Fc2-int & 1 & 3 & 33.33 \\
\hline MIR3 & 849 & 90,205 & 0.94 & HERVE-int & 80 & 250 & 32.00 \\
\hline MIRc & 828 & 102,646 & 0.81 & SVA_F & 278 & 998 & 27.86 \\
\hline MSTA-int & 730 & 3,104 & 23.52 & Tigger2b_Pri & 528 & 2000 & 26.40 \\
\hline L1PB1 & 698 & 13,202 & 5.29 & PABL_A & 126 & 511 & 24.66 \\
\hline MLT2A2 & 646 & 3,865 & 16.71 & MSTB2-int & 22 & 91 & 24.18 \\
\hline MER2O & 608 & 16,569 & 3.67 & MSTA-int & 730 & 3104 & 23.52 \\
\hline L1MC1 & 605 & 12,979 & 4.66 & MER50 & 573 & 2527 & 22.68 \\
\hline MER50 & 573 & 2,527 & 22.68 & LTR14B & 78 & 357 & 21.85 \\
\hline Tigger2 & 546 & 2,735 & 19.96 & MSTB-int & 187 & 866 & 21.59 \\
\hline Tigger2b_Pri & 528 & 2,000 & 26.40 & MER8 & 408 & 1931 & 21.13 \\
\hline L1M5 & 482 & 63,783 & 0.76 & MSTC-int & 38 & 183 & 20.77 \\
\hline MLT1D & 473 & 20,459 & 2.31 & Tigger2 & 546 & 2735 & 19.96 \\
\hline
\end{tabular}

SVA elements, which contain a portion of Alu repeat [49], and L2, MIR and Tigger families of retrotransposons.

\section{Functionality of HNF4 $\alpha$-Alu elements}

Perhaps the most important question is how many of the HNF $4 \alpha$-Alu elements are functional. Several recent studies suggest that Alu elements may indeed play a role in regulating gene expression: Alu elements are

\begin{tabular}{|lcccccc|}
\hline \multicolumn{1}{|c}{ Gene } & Alu family & Marmoset & Rhesus & Orangutan & Chimp & Human \\
\hline ABCC3 & AluSz & + & + & + & + & + \\
ATPIF1 & AluSx1 & + & + & + & + & + \\
PRLR & AluSc8 & + & + & + & + & + \\
TTR & AluJb & + & + & + & + & + \\
APOA4 & AluSx1 & + & + & + & - & + \\
SOCS2 & AluSz & + & + & + & - & + \\
\hline SOD2 & AluSz & + & + & + & + & + \\
CANX & AluSx1 & - & + & + & + & + \\
FEM1A & AluSq2 & - & + & + & + & + \\
GSTM4 & AluSz & - & + & + & + & + \\
$I P 6 K 2$ & AluSg4 & - & + & + & + & + \\
PRODH2 & AluSp & - & + & + & + & + \\
\hline IL32 & AluSq2 & - & - & + & + & + \\
$A P O M$ & AluJr & - & - & + & + & + \\
\hline
\end{tabular}

Figure 6 Gene-specific HNF4 $\alpha$-Alu sequences in primate genomes. Presence (+) and absence (-) of the HNF4 $\alpha$-Alu element in the indicated HNF4 $\alpha$ target genes as determined by ChIP analysis (Figure 3) in all the sequenced primate genomes. Age in millions of years ago (MYA) of the divergence from the primate lineage is given on the right. enriched in regions with genes [50], particularly in housekeeping and metabolism genes. However, they are underrepresented in developmental genes [45], suggesting that their presence in those genes may be detrimental. Binding sites for other NRs have also been found in Alu repeats and several of those sites were found to affect transcription [17,19-21]. To determine what types of genes contain HNF4 $\alpha$-Alu elements, we performed a Gene Ontology (GO) analysis of genes enriched with HNF $4 \alpha$-Alu elements (> 8 per $5 \mathrm{~kb}$ promoter region) and found RNA processing and transcription regulation genes, as well as macromolecular catabolic processes and complex assembly genes (see additional file 2: Table S6 for a full list of significant GO categories and relevant genes). RNA processing is not a category previously associated with classical HNF4 $\alpha$ binding sites, but Alu elements have been found to play a direct role in alternative splicing [51].

In a detailed, genome-wide analysis of functional targets of HNF4 $\alpha$ and binding sites, we recently found that only $30 \%$ of genes down regulated in an HNF4 $\alpha$ RNAi experiment contained a potential classical HNF4 $\alpha$ binding site [42]. While the other $70 \%$ could be indirect targets, it is also possible that some of those genes are regulated by HNF4 $\alpha$-containing Alu elements, consistent with our finding here that on average every gene in the human genome contains $\sim 2.91 \mathrm{HNF} 4 \alpha$-Alu elements within $5000 \mathrm{bp}$ upstream of the TSS. On an 


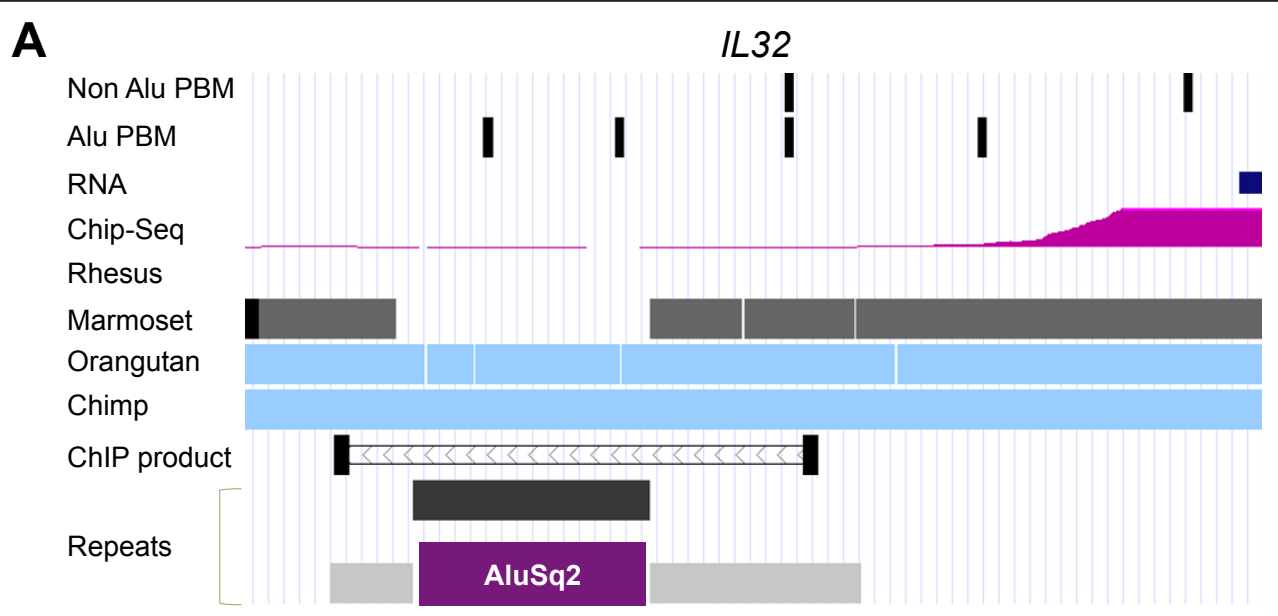

B

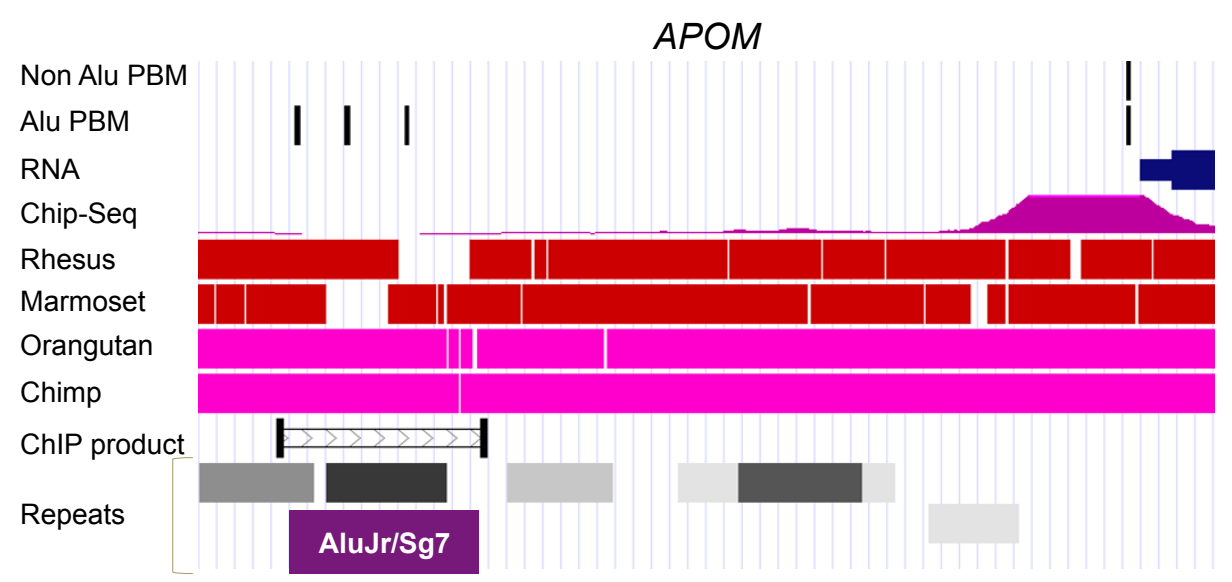

C

\section{PRODH2}

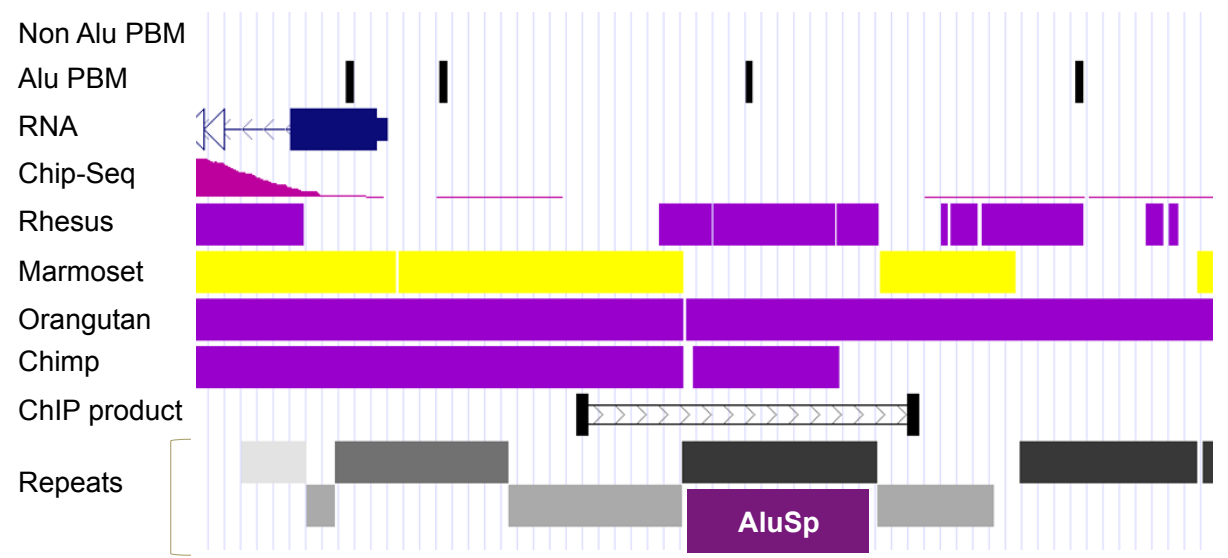

Figure 7 Alu insertions in the promoters of IL32, APOM and PRODH2 genes. Screen shots from UCSC Genome Browser of human and other indicated primate genomes in the region of the HNF4 $\alpha$-Alu element ChIP'd by HNF4 $\alpha$ in the IL32 (A), APOM (B) and PRODH2 (C) genes. Shown from top to bottom in each figure are non Alu HNF4a binding sites from Bolotin et al. [42] (Non Alu PBM); Alu sites from this study (Alu PBM); mRNA from RefSeq track (RNA); HNF4 $\alpha$ ChIP signal in HepG2 from the Custom Track by UC Davis (http://genome.ucsc.edu/ENCODE/) (ChIP-Seq); DNA sequence conservation in four primate genomes (Rhesus, Marmoset, Orangutan, Chimp); PCR product amplified after ChIP in Fig. 3 (ChIP product); repeats from Repeat Masker 3.2.7 with the relevant Alu sequence indicated (Repeats). 
individual gene basis, we found that even though the HNF4 $\alpha$ binding sites in Alu repeats are not high affinity sites compared to the majority of classical HNF4 $\alpha$ sites, they are nonetheless capable of driving the expression of a heterologous gene on their own. In the context of the genome, however, the HNF4 $\alpha$-Alu elements are typically present in conjunction with other TFBS in the promoter, including other HNF4 $\alpha$ binding sites, suggesting that they may act in more of a modulatory capacity than as the sole drivers of transcription, as we observed on the APOA4 promoter. These results are similar to those found for other NRs albeit on different binding sites within the Alu elements [19-21].

The functionality of HNF4 $\alpha$-Alu elements, as with any potential TFBS, will also depend on the state of the local chromatin and the accessibility of the site to HNF4 $\alpha$. While it has been reported that most Alu repeats in the human genome contain $\mathrm{CpG}$ dinucleotides that are methylated [52], potentially rendering them nonfunctional, the Alu elements that are hypomethylated tend to be in promoter regions, suggesting that they are accessible [52,53]. Indeed, our analysis showed that there may be as many as $\sim 46,000$ HNF4 $\alpha$ Alu elements in DNase hypersensitive regions genomewide, suggesting that they may be accessible for binding and therefore may affect transcription.

\section{Alu repeats as a sink for HNF $4 \alpha$ protein?}

In addition to affecting transcription directly, it is tempting to speculate that the relatively large number of HNF $4 \alpha$-Alu elements, especially in regions of open chromatin, could act as a sink or reservoir for HNF4 $\alpha$ protein. We have estimated by semi-quantitative immunoblotting that there may be as many as 450,000 molecules of HNF4 $\alpha$ in the nucleus of an adult mouse hepatocyte (unpublished observation); this estimate is consistent with the fact that we originally had to purify HNF $4 \alpha$ only $\sim 5,000$ to 10,000 -fold from adult rat liver nuclei [54]. Assuming that human hepatocytes have similar levels of HNF4 $\alpha$ protein and keeping in mind that HNF4 $\alpha$ binds DNA only as a dimer [36], this suggests that the presence of $\sim 7000$ to $46,000 \mathrm{HNF} 4 \alpha$-Alu elements in accessible regions of the genome would not have a significant impact on the availability of $\sim 225,000$ HNF4 $\alpha$ protein dimers in a normal adult hepatocyte nucleus. However, conditions that significantly alter the accessibility of the $\sim 750,000 \mathrm{HNF} 4 \alpha$-Alu elements genome-wide, or the amount of HNF4 $\alpha$ protein, could in theory result in a situation in which the stoichiometry of $\mathrm{HNF} 4 \alpha$-Alu sites to HNF4 $\alpha$ protein is indeed relevant. For example, global loss of DNA methylation has been associated with cancer progression and there is at least one report in which certain Alu elements lose methylation during tumor progression [55]. Likewise, a decrease in the amount of functional HNF4 $\alpha$ protein, such as that found in heterozygous MODY1 patients [31], activation of signaling pathways [56-61], DNA damage via p53 [62,63], microRNAs [64], diet [35,65,66] and diseases such as colitis and cancer $[67,68]$ could tip the balance between HNF4 $\alpha$ protein and potential binding sites, rendering the notion of Alu elements as a sink of HNF $4 \alpha$ potentially relevant. The stoichiometry of HNF4 $\alpha$ protein to total HNF4 $\alpha$ binding sites may also differ in other tissues and developmental time points [69], which could alter the relevance of HNF4 $\alpha$-Alu elements.

\section{Conclusion}

The $\sim 1.2$ million HNF4 $\alpha$ binding sites in $~ 750,000$ Alu elements in the human genome has the potential to affect the expression of HNF4 $\alpha$ target genes. Therefore, it will be important to keep the HNF4 $\alpha$-Alu elements in mind when investigating HNF4 $\alpha$ function, especially when using non primates as models for humans and when investigating conditions, such as cancer, where there may be genome-scale alterations in chromatin accessibility. These results join the increasing number of reports of NR and other TF binding sites in Alu or other repeat elements [70] and support the notion that repetitive DNA may be more than just "junk" DNA.

\section{Methods}

\section{PBM design and analysis}

A custom-designed 8x15k Alu PBM (PBM3) containing 8 grids, each of which consisted of $\sim 15,000$ spots of DNA, was ordered from Agilent (Figure 1). An in silico Alu library of $\sim 200$ DNA sequences was made by extracting every unique 13-mer from every Alu element consensus from the RepBase database (http://www.girinst.org/repbase/). The human genome (hg18) was searched with the Alu library and the 100 most frequent sites were included on PBM3. The 13-mer Alu library was further searched with the support vector machine (SVM) model described in Bolotin et al [42]. (The SVM is an algorithm trained on sequences bound by HNF4 $\alpha$ in the PBM; it predicts the binding HNF4 $\alpha$ binding with correlation $\mathrm{R}^{2}=0.76$.) The top 100 scoring potential HNF4 $\alpha$ binding sites from the SVM search were included on PBM3 for a total of 200-derived Alu sequences. Another 704 sequences were included from permutations of three adjacent positions in every combination of the DR1 consensus (5'-AGGTCAaAGGTCA$\left.3^{\prime}\right)$ and 768 sequences from similar permutations of a DR2 consensus (5'-AGGTCAaaAGGTCA-3'). Additionally, 100 randomly generated 13 -mers and 50 randomly generated 14-mers were included as negative controls for the DR1s and DR2s, respectively. Finally, an additional 2,061 unique sequences were generated from an 
SVM search of all human genes for a total of 3802 unique DNA sequences, each of which was replicated 4 times on the PBM for a total of 15,208 DNA spots. The linker and cap sequences were the same as those described in Bolotin et al. [42]. (See additional file 2: Table S5 for a list of all DNA sequences on PBM3 and the corresponding HNF4 $\alpha$ binding score.)

Crude nuclear extracts of COS-7 cells transfected with human HNF4 $\alpha 2$ or HNF $4 \alpha 8$ expression vectors was applied to PBM3 ( $400 \mathrm{ng}$ HNF4 $\alpha$ protein per grid) and visualized and analyzed as described in Bolotin et al. [42]. The primary antibody was a mouse monoclonal that recognizes the C-terminal region of HNF4 $\alpha$ (H1415 from R\&D Systems); the secondary was NL-637 antiMouse IgG (NL008 from R\&D Systems). PBMs were scanned using a GenePix Axon 4000B scanner (Molecular Devices, Sunnyvale, CA) at $543 \mathrm{~nm}$ (Cy3) dUTP and $633 \mathrm{~nm}$ (Cy5-conjugated secondary antibody). Since there was no significant difference between the HNF4 $\alpha 2$ and HNF4 $\alpha 8$ isoforms, which differ by $\sim 30$ amino acids in the N-terminal region but have identical DNA binding and dimerization/ligand binding domains, the average of the four grids (two with HNF4 $\alpha 2$ and two with HNF4 $\alpha$ 8) were used for the final PBM3 score. The sequences with a score $>0.612$ (i.e., $2 \mathrm{SD}$ above the mean of the random controls, p-value $<.045)$ were considered to be HNF4 $\alpha$ binders.

\section{ChIP and RNAi Expression Profiling}

HNF $4 \alpha$ ChIP from HepG2 cells was performed as described in [71]. Quantitative-PCR (qPCR) following the ChIP was performed using BioRad IQ SYBR Green Supermix. Each 23.5-ul reaction included $12.5 \mathrm{ul}$ of Supermix, $0.25 \mathrm{ul}$ of $100 \mathrm{nmol}$ of each primer, $0.5 \mathrm{ul}$ of template and $10 \mathrm{ul}$ of ddH2O. The qPCR was performed as follows: $95^{\circ} \mathrm{C}$ for $5 \mathrm{~min}$ (hot start), followed by 40 cycles $95^{\circ} \mathrm{C}$ for $30 \mathrm{sec}$ (melt), $30 \mathrm{sec}$ at the melting temperature $(\mathrm{Tm})$ for annealing and extension, followed by a melt curve. The Tm was determined experimentally for each pair of primers by using a temperature gradient qPCR that was visualized on an ethidium bromidestained agarose gel to control for product size. All qPCR was performed using BioRad iQ5 and myQ5 thermocyclers. (See additional file 2: Table $\mathbf{S 2}$ for a complete list of PCR primers giving a positive ChIP signal.) Affymetrix expression profiling data for the HNF $4 \alpha$ RNAi knockdown in HepG2 cells were obtained from Bolotin et al. [42].

\section{Luciferase assay}

Human embryonic kidney (HEK 293T) cells were plated $\left(0.25 \times 10^{6}\right.$ cells $)$ in 12 -well plates. After $24 \mathrm{hr}$ the cells were transfected using Lipofectamine 2000 according to the manufacturer's protocol (Invitrogen), with different amounts of empty vector (pcDNA3) or wild type human HNF4 $\alpha 2$ in pcDNA3, $1 \mu \mathrm{g}$ of the luciferase reporter and $200 \mathrm{ng}$ of a CMV. $\beta$ gal control. Cells were harvested after $24 \mathrm{hr}$ using Triton lysis buffer (1\% Triton X-100, 25 mM Gly-Gly pH 7.8, 15 mM MgSO4, 4 $\mathrm{mM}$ EGTA, $1 \mathrm{mM}$ DTT). Luciferase and $\beta$-gal activity were measured as described earlier [62]. Significant differences in luciferase activity between cells transfected with empty vector or human HNF4 $\alpha 2$ were determined by the Student's $t$-test. APOM, PRODH2 and TTR luciferase constructs were created by cloning PCR products of the Alu elements in the respective promoters into pGL4.23 (Promega): the APOM construct used SfiI restriction sites and the $P R O D H 2$ and TTR constructs used NheI and KpnI sites. The APOA4.Luc construct was made by cloning a PCR product from the human APOA4 promoter (-1343 to +247) into the pGL4.10 vector (Promega) at HindIII and NheI sites. Site-directed mutations were introduced into the HNF4 $\alpha$ binding sites in the Alu and PBM elements using the QuikChange kit (Stratagene). Luciferase reporter constructs with classical HNF4 $\alpha$ response elements (RE-1 and RE2) were made by inserting the appropriate synthetic oligonucleotides into pGL4.23. All constructs were sequence verified. (See additional file 2: Table S2 for the sequence of the PCR primers and oligonucleotides used in the constructions.)

\section{Bioinformatic searches}

Searches of human genome hg18 downloaded from UCSC Genome Browser (http://genome.ucsc.edu) were conducted using all of the sequences that HNF4 $\alpha$ bound in PBM3 using Seqmap [72]. Alu and non Alu repeats with HNF4 $\alpha$ sites were identified by comparing the HNF4 $\alpha$ genome-wide search results to the repeat coordinates obtained from Repeat Masker Track version 3.2.7 in UCSC Genome Browser. The results were processed using custom Perl scripts and an SQL database. To determine accessibility of HNF4 $\alpha$-Alu sites, we used BEDtools software package [73] to cross reference our list of $\sim 750,000$ HNF4 $\alpha$-Alu elements (Table 2) with DNase hypersensitivity tracks in the ENCODE Project in UCSC Genome Bioinformatics, allowing for one nucleotide or more of overlap. We used both the clustered track that contains data from multiple human cell lines (http://genome.ucsc.edu/cgi-bin/hgTrackUi? hgsid $=211217271 \& g=$ wgEncodeRegDnaseClustered) as well as tracks for two different repetitions of HepG2 cells (http://genome.ucsc.edu/cgi-bin/hgTrackUi? $\mathrm{db}=\mathrm{hg} 18 \& \mathrm{~g}=$ wgEncodeUwDnaseSeq). Gene Ontology analysis of genes containing HNF4 $\alpha$-Alu elements was done using DAVID [74]. We used as a cut off eight HNF4 $\alpha$-Alu elements within $5 \mathrm{~kb}$ upstream of +1 , two SD above the average number of sites $(2.91+4.22)$. 


\section{Additional material}

Additional file 1: Overrepresentation of Alu-related HNF4 $\alpha$ binding motif $(\mathbf{H} 4.141)$ in the human genome. Frequency profile of 217

HNF $4 \alpha$ binding sites identified by gel shift assays and derived from the literature in the human and mouse genomes.

Additional file 2: Supplementary Tables. Six tables with frequencies of HNF $4 \alpha$ binding sites in repetitive DNA, complete PBM and GO results, and primers used in this study.

\section{Acknowledgements and funding}

We thank D. Mane-Padros and L. Vuong for the luciferase constructs with classical HNF $4 \alpha$ response elements and B. Fang for predicting mutations in HNF4 $\alpha$ binding sites. This work was funded by a PhRMA Foundation fellowship to EB, and grants to FMS from the UCR Institute for Integrative Genome Biology and the NIH (R21 MH087397, R01 DK053892). KC, W H-V, CY and JMS were supported by NIH R01 DK053892. EB was supported by $\mathrm{NIH}$ R21 MH087397. The funding bodies did not have any role in the study design, data collection, manuscript preparation or submission.

\section{Author details}

'Department of Cell Biology and Neuroscience, University of California, Riverside, Riverside, CA, 92521, USA. ${ }^{2}$ Institute for Integrative Genome Biology, University of California, Riverside, Riverside, CA, 92521, USA. ${ }^{3} \mathrm{CHORI}$ (Children's Hospital Oakland Research Institute), 5700 Martin Luther King Jr Way, Oakland, CA 94609, USA. ${ }^{4}$ Genomics Research Center, Academia Sinica, No. 128 Academia Road, Section 2, Nankang District, Taipei 115, Taiwan. ${ }^{5}$ Roche Diagnostics Shanghai Limited, 1045 Central Huaihai Road, Shanghai 200031, China.

\section{Authors' contributions}

EB designed and carried out the PBM, designed the primers for the ChIP and carried out the PCR, made luciferase constructs, performed all the bioinformatics analysis and drafted the manuscript; KC carried out the luciferase assays and helped with figures; W H-V carried out the ChIP assay; CY made the initial observation of HNF4 sites in Alu elements; JMS made luciferase reporter constructs and mutants; FMS was involved in all aspects of the design of the experiments, analysis of the results and preparation of the manuscript. All authors proof-read the manuscript.

Received: 18 March 2011 Accepted: 15 November 2011

Published: 15 November 2011

\section{References}

1. Lander $E S$, Linton $L M$, Birren $B, C N$, et al: Initial sequencing and analysis of the human genome. Nature 2001, 409(6822):860-921.

2. Ohno S: So much "junk" DNA in our genome. Brookhaven Symp Biol 1972, 23:366-370.

3. van de Lagemaat LN, Landry JR, Mager DL, Medstrand P: Transposable elements in mammals promote regulatory variation and diversification of genes with specialized functions. Trends Genet 2003, 19(10):530-536.

4. Davidson $\mathrm{EH}$, Britten RJ: Organization, transcription, and regulation in the animal genome. Q Rev Biol 1973, 48(4):565-613.

5. Orgel LE, Crick FH: Selfish DNA: the ultimate parasite. Nature 1980, 284(5757):604-607.

6. Ullu E, Tschudi C: Alu sequences are processed 7SL RNA genes. Nature 1984, 312(5990):171-172

7. Rubin CM, Houck CM, Deininger PL, Friedmann T, Schmid CW: Partial nucleotide sequence of the 300-nucleotide interspersed repeated human DNA sequences. Nature 1980, 284(5754):372-374.

8. Houck CM, Rinehart FP, Schmid CW: A ubiquitous family of repeated DNA sequences in the human genome. J Mol Biol 1979, 132(3):289-306.

9. Batzer MA, Deininger PL: Alu repeats and human genomic diversity. Nat Rev Genet 2002, 3(5):370-379.

10. Liu GE, Alkan C, Jiang L, Zhao S, Eichler EE: Comparative analysis of Alu repeats in primate genomes. Genome Res 2009, 19(5):876-885.

11. Deininger $P L$, Batzer MA: Alu repeats and human disease. Mol Genet Metab 1999, 67(3):183-193.
12. Kreahling J, Graveley BR: The origins and implications of Aluternative splicing. Trends Genet 2004, 20(1):1-4.

13. Humphrey GW, Englander EW, Howard BH: Specific binding sites for a pol III transcriptional repressor and pol II transcription factor YY1 within the internucleosomal spacer region in primate Alu repetitive elements. Gene Expr 1996, 6(3):151-168.

14. Oei S-L, Babich VS, Kazakov VI, Usmanova NM, Kropotov AV, Tomilin NV: Clusters of regulatory signals for RNA polymerase II transcription associated with Alu family repeats and CpG islands in human promoters. Genomics 2004, 83(5):873-882.

15. Cui F, Sirotin MV, Zhurkin VB: Impact of Alu repeats on the evolution of human p53 binding sites. Biol Direct 2011, 6(1):2.

16. Thornburg BG, Gotea V, Makaowski W: Transposable elements as a significant source of transcription regulating signals. Gene 2006, 365:104-110.

17. Laperriere D, Wang T-T, White JH, Mader S: Widespread Alu repeat-driven expansion of consensus DR2 retinoic acid response elements during primate evolution. BMC Genomics 2007, 8:23.

18. Norris J, Fan D, Aleman C, Marks JR, Futreal PA, Wiseman RW, Iglehart JD, Deininger PL, McDonnell DP: Identification of a new subclass of Alu DNA repeats which can function as estrogen receptor-dependent transcriptional enhancers. J Biol Chem 1995, 270(39):22777-22782.

19. Mason CE, Shu FJ, Wang C, Session RM, Kallen RG, Sidell N, Yu T, Liu MH, Cheung $E$, Kallen CB: Location analysis for the estrogen receptor-alpha reveals binding to diverse ERE sequences and widespread binding within repetitive DNA elements. Nucleic Acids Res 2010, 38(7):2355-2368.

20. Jacobsen BM, Jambal P, Schittone SA, Horwitz KB: ALU repeats in promoters are position-dependent co-response elements (coRE) that enhance or repress transcription by dimeric and monomeric progesterone receptors. Mol Endocrinol 2009, 23(7):989-1000.

21. Gombart AF, Saito T, Koeffler HP: Exaptation of an ancient Alu short interspersed element provides a highly conserved vitamin D-mediated innate immune response in humans and primates. BMC Genomics 2009, 10:321.

22. Britten RJ: DNA sequence insertion and evolutionary variation in gene regulation. Proceedings of the National Academy of Sciences of the United States of America 1996, 93(18):9374-9377.

23. Bolotin E, Schnabl J, Sladek F: HNF4A (Homo sapiens). Transcription Factor Encyclopedia 2009 [http://burgundy.cmmt.ubc.ca/cgi-bin/tfe/home.pl].

24. Hayhurst GP, Lee YH, Lambert G, Ward JM, Gonzalez FJ: Hepatocyte nuclear factor 4alpha (nuclear receptor 2A1) is essential for maintenance of hepatic gene expression and lipid homeostasis. Mol Cell Biol 2001, 21:1393-1403.

25. Watt AJ, Garrison WD, Duncan SA: HNF4: a central regulator of hepatocyte differentiation and function. Hepatology 2003, 37:1249-1253.

26. Babeu JP, Darsigny M, Lussier CR, Boudreau F: Hepatocyte nuclear factor 4alpha contributes to an intestinal epithelial phenotype in vitro and plays a partial role in mouse intestinal epithelium differentiation. Am J Physiol Gastrointest Liver Physiol 2009, 297(1):G124-134.

27. Cattin AL, Le Beyec J, Barreau F, Saint-Just S, Houllier A, Gonzalez FJ, Robine S, Pincon-Raymond M, Cardot P, Lacasa M, et al: Hepatocyte nuclear factor 4alpha, a key factor for homeostasis, cell architecture, and barrier function of the adult intestinal epithelium. Mol Cell Biol 2009, 29(23):6294-6308.

28. Darsigny M, Babeu JP, Dupuis AA, Furth EE, Seidman EG, Levy E, Verdu EF, Gendron FP, Boudreau F: Loss of hepatocyte-nuclear-factor-4alpha affects colonic ion transport and causes chronic inflammation resembling inflammatory bowel disease in mice. PLoS One 2009, 4(10):e7609.

29. Yamagata K, Furuta H, Oda N, Kaisaki PJ, Menzel S, Cox NJ, Fajans SS, Signorini S, Stoffel M, Bell Gl: Mutations in the hepatocyte nuclear factor4alpha gene in maturity-onset diabetes of the young (MODY1). Nature 1996, 384(6608):458-460.

30. Barrett JC, Lee JC, Lees CW, Prescott NJ, Anderson CA, Phillips A, Wesley E, Parnell K, Zhang H, Drummond $\mathrm{H}$, et al: Genome-wide association study of ulcerative colitis identifies three new susceptibility loci, including the HNF4A region. Nat Genet 2009, 41(12):1330-1334.

31. Ryffel GU: Mutations in the human genes encoding the transcription factors of the hepatocyte nuclear factor (HNF)1 and HNF4 families: functional and pathological consequences. J Mol Endocrinol 2001, 27(1):11-29. 
32. Sladek F, Seidel S: Hepatocyte nuclear factor 4 alpha. Nuclear Receptors and Genetic Diseases London: Academic Press; 2001, 309-361.

33. Overington JP, Al-Lazikani B, Hopkins AL: How many drug targets are there? Nat Rev Drug Discov 2006, 5(12):993-996.

34. Hwang-Verslues WW, Sladek FM: HNF4alpha-role in drug metabolism and potential drug target? Curr Opin Pharmacol 2010, 10(6):698-705.

35. Yuan X, Ta TC, Lin M, Evans JR, Dong Y, Bolotin E, Sherman MA, Forman BM, Sladek FM: Identification of an endogenous ligand bound to a native orphan nuclear receptor. PLoS ONE 2009, 4:e5609.

36. Jiang G, Nepomuceno L, Hopkins K, Sladek FM: Exclusive homodimerization of the orphan receptor hepatocyte nuclear factor 4 defines a new subclass of nuclear receptors. Mol Cell Biol 1995, 15:5131-5143.

37. Sladek FM: What are nuclear receptor ligands? Mol Cell Endocrinol 2011, 334(1-2):3-13.

38. Bridgham JT, Eick GN, Larroux C, Deshpande K, Harms MJ, Gauthier ME, Ortlund EA, Degnan BM, Thornton JW: Protein evolution by molecular tinkering: diversification of the nuclear receptor superfamily from a ligand-dependent ancestor. PLOS Biol 2010, 8(10).

39. Ellrott $K$, Yang C, Sladek FM, Jiang T: Identifying transcription factor binding sites through Markov chain optimization. Bioinformatics (Oxford, England) 2002, 18(Suppl 2):S100-109.

40. Odom DT, Zizlsperger N, Gordon DB, Bell GW, Rinaldi NJ, Murray HL, Volkert TL, Schreiber J, Rolfe PA, Gifford DK, et al: Control of pancreas and liver gene expression by HNF transcription factors. Science 2004, 303:1378-1381.

41. Odom DT, Dowell RD, Jacobsen ES, Nekludova L, Rolfe PA, Danford TW, Gifford DK, Fraenkel E, Bell Gl, Young RA: Core transcriptional regulatory circuitry in human hepatocytes. Mol Syst Biol 2006, 2:2006 0017.

42. Bolotin E, Liao H, Ta TC, Yang C, Hwang-Verslues W, Evans JR, Jiang T, Sladek FM: Integrated approach for the identification of human hepatocyte nuclear factor 4 alpha target genes using protein binding microarrays. Hepatology 2010, 51(2):642-653.

43. Jiang G, Sladek FM: The DNA binding domain of hepatocyte nuclear factor 4 mediates cooperative, specific binding to DNA and heterodimerization with the retinoid $\times$ receptor alpha. J Biol Chem 1997, 272:1218-1225

44. Quentin Y: Origin of the Alu family: a family of Alu-like monomers gave birth to the left and the right arms of the Alu elements. Nucleic Acids Res 1992, 20(13):3397-3401.

45. Polak P, Domany E: Alu elements contain many binding sites for transcription factors and may play a role in regulation of developmental processes. BMC Genomics 2006, 7:133.

46. Sabo PJ, Kuehn MS, Thurman R, Johnson BE, Johnson EM, Cao H, Yu M, Rosenzweig E, Goldy J, Haydock A, et al: Genome-scale mapping of DNase I sensitivity in vivo using tiling DNA microarrays. Nat Methods 2006, 3(7):511-518.

47. Sabo PJ, Hawrylycz M, Wallace JC, Humbert R, Yu M, Shafer A, Kawamoto J, Hall R, Mack J, Dorschner MO, et al: Discovery of functional noncoding elements by digital analysis of chromatin structure. Proceedings of the National Academy of Sciences of the United States of America 2004, 101(48):16837-16842

48. Goodman M: The genomic record of Humankind's evolutionary roots. Am J Hum Genet 1999, 64(1):31-39.

49. Ostertag EM, Goodier JL, Zhang Y, Kazazian HH Jr: SVA elements are nonautonomous retrotransposons that cause disease in humans. Am J Hum Genet 2003, 73(6):1444-1451.

50. Grover D, Mukerji M, Bhatnagar P, Kannan K, Brahmachari SK: Alu repeat analysis in the complete human genome: trends and variations with respect to genomic composition. Bioinformatics (Oxford, England) 2004, 20(6):813-817.

51. Kreahling J, Graveley BR: The origins and implications of Aluternative splicing. Trends Genet 2004, 20(1):1-4.

52. Xie H, Wang M, Bonaldo Mde F, Smith C, Rajaram V, Goldman S, Tomita T, Soares MB: High-throughput sequence-based epigenomic analysis of Alu repeats in human cerebellum. Nucleic Acids Res 2009, 37(13):4331-4340.

53. Xie H, Wang M, de Andrade A, Bonaldo Mde F, Galat V, Arndt K, Rajaram V, Goldman S, Tomita T, Soares MB: Genome-wide quantitative assessment of variation in DNA methylation patterns. Nucleic Acids Res 2011, 39(10):4099-4108.
54. Sladek FM, Zhong WM, Lai E, Darnell JE Jr: Liver-enriched transcription factor HNF-4 is a novel member of the steroid hormone receptor superfamily. Genes Dev 1990, 4(12B):2353-2365.

55. Xie H, Wang M, Bonaldo Mde F, Rajaram V, Stellpflug W, Smith C, Arndt K, Goldman S, Tomita T, Soares MB: Epigenomic analysis of Alu repeats in human ependymomas. Proceedings of the National Academy of Sciences of the United States of America 2010, 107(15):6952-6957.

56. Sun K, Montana V, Chellappa K, Brelivet Y, Moras D, Maeda Y, Parpura V, Paschal BM, Sladek FM: Phosphorylation of a conserved serine in the deoxyribonucleic acid binding domain of nuclear receptors alters intracellular localization. Mol Endocrinol 2007, 21(6):1297-1311.

57. Xie X, Liao H, Dang H, Pang W, Guan Y, Wang X, Shyy JY, Zhu Y, Sladek FM: Down-regulation of hepatic HNF4alpha gene expression during hyperinsulinemia via SREBPs. Mol Endocrinol 2009, 23(4):434-443.

58. Hong YH, Varanasi US, Yang W, Leff T: AMP-activated protein kinase regulates HNF4alpha transcriptional activity by inhibiting dimer formation and decreasing protein stability. J Biol Chem 2003, 278(30):27495-27501

59. Leclerc I, Lenzner C, Gourdon L, Vaulont S, Kahn A, Viollet B: Hepatocyte nuclear factor-4alpha involved in type 1 maturity-onset diabetes of the young is a novel target of AMP-activated protein kinase. Diabetes 2001, 50(7):1515-1521.

60. Viollet B, Kahn A, Raymondjean M: Protein kinase A-dependent phosphorylation modulates DNA-binding activity of hepatocyte nuclear factor 4. Mol Cell Biol 1997, 17(8):4208-4219.

61. Hatzis P, Kyrmizi I, Talianidis I: Mitogen-activated protein kinase-mediated disruption of enhancer-promoter communication inhibits hepatocyte nuclear factor 4alpha expression. Mol Cell Biol 2006, 26(19):7017-7029.

62. Maeda Y, Seidel SD, Wei G, Liu X, Sladek FM: Repression of hepatocyte nuclear factor 4alpha tumor suppressor p53: involvement of the ligandbinding domain and histone deacetylase activity. Mol Endocrinol 2002, 16(2):402-410.

63. Maeda Y, Hwang-Verslues WW, Wei G, Fukazawa T, Durbin ML, Owen LB, Liu X, Sladek FM: Tumour suppressor p53 down-regulates the expression of the human hepatocyte nuclear factor 4alpha (HNF4alpha) gene. Biochem J 2006, 400(2):303-313.

64. Takagi S, Nakajima M, Kida K, Yamaura Y, Fukami T, Yokoi T: MicroRNAs regulate human hepatocyte nuclear factor 4alpha, modulating the expression of metabolic enzymes and cell cycle. J Biol Chem 2010, 285(7):4415-4422.

65. Selva DM, Hogeveen KN, Innis SM, Hammond GL: Monosaccharideinduced lipogenesis regulates the human hepatic sex hormone-binding globulin gene. J Clin Invest 2007, 117(12):3979-3987.

66. Chiang JY: Regulation of bile acid synthesis: pathways, nuclear receptors, and mechanisms. J Hepatol 2004, 40(3):539-551.

67. Tanaka T, Jiang S, Hotta H, Takano K, Iwanari H, Sumi K, Daigo K, Ohashi R, Sugai $\mathrm{M}$, lkegame $\mathrm{C}$, et al: Dysregulated expression of $\mathrm{P} 1$ and $\mathrm{P} 2$ promoter-driven hepatocyte nuclear factor-4alpha in the pathogenesis of human cancer. J Pathol 2006, 208:662-672.

68. Ahn SH, Shah YM, Inoue J, Morimura K, Kim I, Yim S, Lambert G, Kurotani R, Nagashima K, Gonzalez FJ, et al: Hepatocyte nuclear factor 4alpha in the intestinal epithelial cells protects against inflammatory bowel disease. Inflamm Bowel Dis 2008, 14(7):908-920.

69. Briancon N, Weiss MC: In vivo role of the HNF4alpha AF-1 activation domain revealed by exon swapping. Embo J 2006, 25(6):1253-1262.

70. Bourque G, Leong B, Vega VB, Chen X, Lee YL, Srinivasan KG, Chew IL, Ruan Y, Wei $\mathrm{CL}, \mathrm{Ng} \mathrm{HH}$, et al: Evolution of the mammalian transcription factor binding repertoire via transposable elements. Genome Res 2008, 18(11):1752-1762.

71. Hwang-Verslues WW, Sladek FM: Nuclear receptor hepatocyte nuclear factor 4alpha1 competes with oncoprotein c-Myc for control of the p21/ WAF1 promoter. Mol Endocrinol 2008, 22:78-90.

72. Jiang $H$, Wong WH: SeqMap: mapping massive amount of oligonucleotides to the genome. Bioinformatics (Oxford, England) 2008, 24(20):2395-2396.

73. Quinlan AR, Hall IM: BEDTools: a flexible suite of utilities for comparing genomic features. Bioinformatics (Oxford, England) 2010, 26(6):841-842.

74. Huang da W, Sherman BT, Lempicki RA: Systematic and integrative analysis of large gene lists using DAVID bioinformatics resources. Nat Protoc 2009, 4(1):44-57. 
75. Jurka J: Evolutionary impact of human Alu repetitive elements. Curr Opin Genet Dev 2004, 14(6):603-608.

76. Crooks GE, Hon G, Chandonia JM, Brenner SE: WebLogo: a sequence logo generator. Genome Res 2004, 14:1188-1190.

doi:10.1186/1471-2164-12-560

Cite this article as: Bolotin et al:: Nuclear Receptor HNF4 $\alpha$ Binding

Sequences are Widespread in Alu Repeats. BMC Genomics 2011 12:560.

Submit your next manuscript to BioMed Central and take full advantage of:

- Convenient online submission

- Thorough peer review

- No space constraints or color figure charges

- Immediate publication on acceptance

- Inclusion in PubMed, CAS, Scopus and Google Scholar

- Research which is freely available for redistribution

Submit your manuscript at 